\title{
CHROMIUM (III) PRODUCES DISTINCT TYPE OF CELL DEATH IN CULTURED CELLS
}

\author{
Emil Rudolf, Miroslav Červinka \\ Charles University in Prague, Faculty of Medicine in Hradec Králové: Department of Medical Biology and Genetics
}

\begin{abstract}
Summary: Chromium acetate hydroxide is a chemical form of trivalent chromium (Cr III) originating from industrial processes. Although considered relatively nontoxic, upon longer treatment intervals it may cause irreversible cellular damage culminating in cell death. In our present work we have attempted to analyze some of the mechanisms whereby this chemical inflicts damage while focusing on the final observed endpoints. We report that $1 \mathrm{mM}$ chromium acetate hydroxide is during weeks lasting treatment capable of injuring the plasma membrane of Hep-2 cells, which in turn becomes permeable to $\mathrm{Cr}$ (III) ions. Analyses of several markers of cellular damage; i.e. mitochondrial activity, nuclear integrity and oxidative stress have shown that tested compound interacts directly with subcellular organelles and upon tested concentration and time induces distinct type of cell death bearing features of apoptosis and necrosis.
\end{abstract}

Key words: Hep-2 cells; Chromium (III); Caspase-3; Apoptosis; Mitochondria; In vitro

\section{Introduction}

Heavy metals constitute an important group of industrially used compounds. Their general importance and assets are, however, downgraded by their toxicity which is in many cases responsible for serious health problems in individuals who are exposed to them. This is the particular case of chromium.

Chromium may exist in several valence states, with trivalent chromium (Cr III) and hexavalent chromium $(\mathrm{Cr}$ VI) being the most stable and common in nature (3). Unlike Cr (VI) whose cytotoxic, genotoxic and carcinogenic properties have been thoroughly tested and verified, $\mathrm{Cr}$ (III) appears to be relatively harmless and its toxicity is up to 1000 times lower $(4,27,28)$. The absence of toxic effects in the presence of $\mathrm{Cr}$ (III) is attributed to its poor transport across biological membranes. Still, several reports have shown that some Cr (III) compounds may penetrate through the plasma membrane upon specific circumstances such as higher employed concentrations or longer exposure periods. Furthermore, chemical form of $\mathrm{Cr}$ (III) appears to be important too as some organic ligands most probably facilitate the entry of $\mathrm{Cr}$ (III) ions to the cell $(2,11,26)$. Once inside the cell, Cr (III) ions may interact with various targets including microfilaments, mitochondria, lysosomes and nucleus or interfere with intracellular signaling pathways by inducing oxidative stress. The final outcome is often necrosis but there are reports about apoptosis as well $(4,18,22)$.
Chromium acetate hydroxide is a chemical form of $\mathrm{Cr}$ (III) which is contained in industrially produced wastes. In our previous work we have shown that this compound has at higher concentration range significant toxic potential which causes immediate cell death by fixation or slower necrosis. In addition, short term testing revealed dose-dependent activity of chromium acetate hydroxide where a limit concentration seemed to be $1 \mathrm{mM}$ which tested negative during 4 days lasting treatment (18).

The purpose of this study was to characterize effects of longer exposure of chromium acetate hydroxide on Hep-2 cells while paying attention to possible mechanisms and final endpoints.

\section{Materials and Methods}

\section{Chemicals}

Chromium acetate hydroxide was purchased from Sigma-Aldrich (Prague, Czech Republic). The stock solution of $1 \mathrm{M}$ was prepared by dissolving the chemical in a serum-free Dulbecco's modified Eagle's medium (DMEM) and stored in a refrigerator until use. Tested concentrations were obtained by diluting the stock in DMEM supplemented with serum.

Buthionine sulfoximine (BSO); N-acetylcystein (NCA); horseradish peroxidase, DAPI (4', 6-diamidino-2-phenylindole), Triton-X, acridine orange/ethidium bromide and trypan blue were obtained from Sigma-Aldrich (Prague, Czech Republic). Monospecific antiserum for the detection 
of activated caspase-3 was obtained from New England Biolabs, Inc. (New England Biolabs, Beverly, U.S.A.). Secondary antibodies were from Molecular Probes, Inc. (Molecular Probes, Eugene, U.S.A.) and from EXBIO (Prague, Czech Republic). All other chemicals were from SigmaAldrich (Prague, Czech Republic).

\section{Cell line}

Human laryngeal cell line Hep-2 (EATCC, No. 86030501, Porton Down, United Kingdom) was maintained as stationary monolayer in plastic tissue-culture dishes (Nunclon, Roskilde, Denmark). Cells were grown in DMEM (Sevapharma, Prague, Czech Republic), supplemented with $10 \%$ bovine serum (Bioveta, Ivanovice, Czech Republic), $100 \mathrm{U} / \mathrm{ml}$ penicillin, and $100 \mu \mathrm{g} / \mathrm{ml}$ streptomycin. Cells were passaged every third day using $0.25 \%$ trypsin and only mycoplasma-free cultures were chosen for experiments.

\section{Cell viability}

The viability of exposed and control Hep-2 cells was evaluated by the trypan blue exclusion test. Cells were trypsinized, resuspended in trypan blue solution $(0.2 \% \mathrm{w} / \mathrm{v})$ and viability was examined at different time points during 3 weeks incubation period.

\section{Dynamic morphology of cells}

Cultures of Hep-2 cells were exposed to $1 \mathrm{mM}$ chromium acetate hydroxide and kept in its presence for 3 weeks. Cells were passaged upon reaching confluence and at regular intervals their morphological appearance was photographed under the inverted microscope Olympus IX-70 (Olympus Optical Co, Ltd., Tokyo, Japan) by digital camera Olympus C-4040 (Olympus Optical CO, Ltd., Tokyo, Japan).

\section{Visualization of F-actin}

Hep-2 cells were fixed with $1 \mathrm{ml}$ of $2 \%$ paraformaldehyde and permeabilized with $1 \mathrm{ml}$ of $0.1 \%$ Triton $\mathrm{X}$ solution. The cells were then stained with FITC conjugated phalloidin at concentration of $10 \mu \mathrm{g} / \mathrm{ml}$ for 30 minutes, post-labeled with DAPI and mounted into SlowFade ${ }^{\circledR}$ medium (Molecular Probes, Inc. Eugene, U.S.A.). The localization and status of F-actin cables were examined under the fluorescence microscope Nikon Eclipse E 400 (Nikon Corporation, Kanagawa, Japan) equipped with the digital camera COOL 1300 (VDS, Vosskühler, Germany), using an excitation filter $450-490 \mathrm{~nm}$ and emission filter $520 \mathrm{~nm}$. Photographs were taken using the software LUCIA DI Image Analysis System LIM (Laboratory Imaging Ltd., Prague, Czech Republic) and analyzed.

\section{Determination of membrane integrity by acridine orange/ethidium bromide uptake}

Treated cells were stained with a mixture of acridine orange/ethidium bromide and observed under a fluores- cence microscope Nikon Eclipse E 400 (Nikon Corporation, Kanagawa, Japan), magnification 400x (excitation filter $450-490 \mathrm{~nm}$, emission filter $520 \mathrm{~nm}$ ). The results were quantified by cell counting in 100 visual fields using the software LUCIA DI Image Analysis System LIM (Laboratory Imaging Ltd., Prague, Czech Republic).

\section{Measurement of oxidative stress}

Hep-2 cells $(6,000$ cells/well) were kept in 96-well microtiter plates and incubated at $37{ }^{\circ} \mathrm{C}$ and $5 \% \mathrm{CO}_{2}$. After each treatment interval, cells were rinsed with PBS and 200 $\mu 1 /$ well of fresh DMEM with horseradish peroxidase and phenol red was added. After one hour the reaction was stopped by sodium hydroxide ( $10 \mu \mathrm{l} /$ well). The absorbance corresponding to the amount of formed hydrogen peroxide was recorded at $620 \mathrm{~nm}$ by a scanning multiwell spectrophotometer Titertec Multiscan MCC/340 (ICN Biochemicals, Frankfurt, Germany). Protein content was determined by bicinchoninic acid assay - BCA assay (Bicinchoninic acid kit for protein determination, Sigma-Aldrich, Prague, Czech Republic). The hydrogen peroxide concentration was expressed as $\mathrm{nM} / \mathrm{mg}$ of protein.

\section{Chromatin staining}

Immunocytochemical detection of activated caspase-3

Detection of the above mentioned markers was carried out as described previously (19). In brief, the slides with fixed cells were rinsed with phosphate saline buffer with Triton X (PBS-T) and a primary antibody was added. After overnight cultivation a secondary antibody (anti-mouse conjugated with Alexa 488) was added, and the cells were incubated for $90 \mathrm{~min}$ at RT. The specimens were optionally post-labeled with DAPI, mounted into SlowFade ${ }^{\circledR}$ medium (Molecular Probes, Inc. Eugene, U.S.A.) and examined under the fluorescence microscope Nikon Eclipse E 400 (Nikon Corporation, Kanagawa) equipped with the digital color matrix camera COOL 1300 (VDS, Vosskühler, Germany), using an excitation filter 330-380 nm and emission filter $420 \mathrm{~nm}$. Photographs were taken using the software LUCIA DI Image Analysis System LIM (Laboratory Imaging Ltd., Prague, Czech Republic) and analyzed. All the experiments were done in triplicate.

\section{Statistics}

Statistical analysis was carried out with a statistical program GraphPad Prism (GraphPad Software, Inc. San Diego, U.S.A.). We used one-way Anova test with Dunnet's post test for multiple comparisons. Results were compared with control samples, and means were considered significant if $\mathrm{P}<0.01$.

\section{Results}

Cytotoxicity of $1 \mathrm{mM}$ chromium acetate hydroxide. In comparison with control cultures, the growth of Hep-2 cells in the presence of $1 \mathrm{mM}$ chromium acetate hydroxide dur- 
ing the first week of cultivation was slowed although not markedly. The slowing became more apparent in the second week of treatment and in the third week the proliferation of exposed cells was inhibited completely. Fig. 1 shows that the viability of treated cells decreased in time too, with the most dramatic reduction being observable at the beginning of the third week. At the end of the third week the viability of all the exposed cells approached zero.

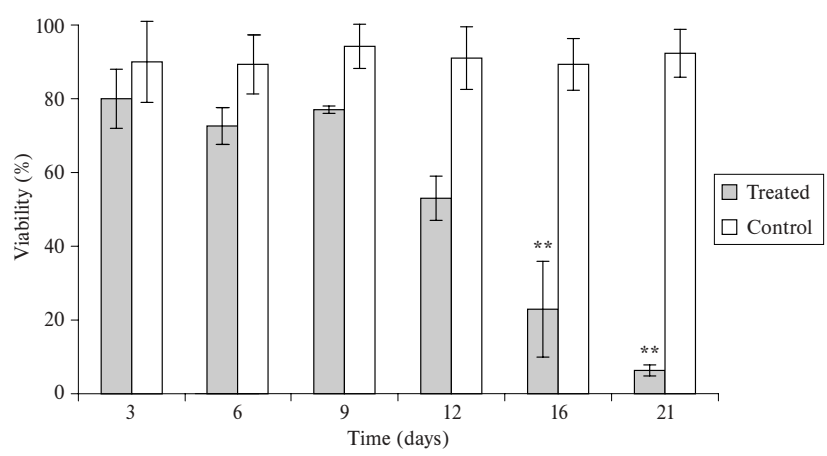

Fig. 1: Viability of human epitelioid laryngeal Hep-2 cells exposed to $1 \mathrm{mM}$ chromium acetate hydroxide during 3 weeks as determined by trypan blue exclusion test. Values represent the mean $\pm \mathrm{SD}$ of three different experiments. $* * \mathrm{P}<0.01$ with one way-Anova test and Dunnet's post test for multiple comparisons.

Morphology of treated cells. There were no observable changes in Hep-2 cells' morphology during the first week of the treatment as compared with controls. From the second week of the treatment, some cells began to change their shape, often dramatically. They extended their bodies thus forming long twisted and bent projections or, conversely,

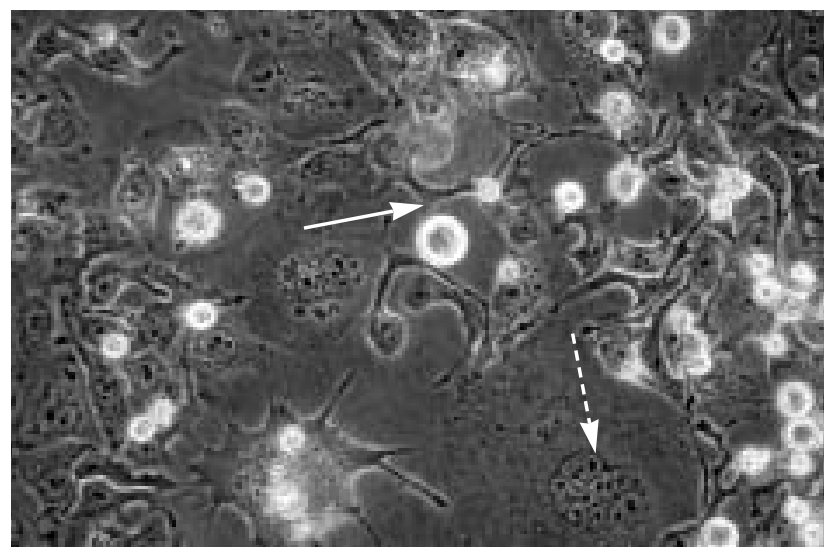

Fig. 2A: Morphology of human epitelioid laryngeal Hep-2 cells after treatment with $1 \mathrm{mM}$ chromium acetate hydroxide two weeks after the beginning of treatment. Full arrow indicates extended cells, dashed arrow denotes multinucleated structure. Phase contrast 400x. shortening and rounding to the shape resembling distended balls. The projections contained numerous F-actin cables undergoing random rearrangements as revealed by fluorescence staining (data not shown). Almost all cells developed extensive vacuolization and were susceptible to mechanically provoked loss of adherence. Furthermore, the number of multinucleated cells increased suggesting incomplete mitotic divisions (Fig. 2).

Integrity of the plasma membrane. Changes in the plasma membrane function and integrity after treatment with 1 $\mathrm{mM}$ chromium acetate hydroxide were detected by staining cells with acridine orange/ethidium bromide solution. This solution takes advantage of two dyes - acridine orange penetrating to intact cells and ethidium bromide selectively staining the nuclei of the cells whose membrane became damaged or otherwise permeable to larger molecules. Unlike the first week of treatment where no ethidium bromide positivity was detected, the proportion of ethidium bromide-positive cells steadily increased over longer exposure periods, reaching maximum during the third week of treatment (Fig. 3).

Oxidative stress. Intracellular chromium metabolism has been shown to be associated with oxidative burst yielding various reactive oxygen species (ROS) such as superoxide anion, singlet oxygen, hydrogen peroxide as well as hydroxyl radicals. The ability of chromium acetate hydroxide to generate hydrogen peroxide in the human laryngeal cells was monitored spectrophotometrically at $620 \mathrm{~nm}$. The levels of hydrogen peroxide in all the analyzed treatment intervals were found to be only slightly elevated when compared with control cultures. Furthermore, pretreatment of cells with BSO - glutathione depleting and NAC - glutathione enhancing compounds had no effect on the levels of oxidative stress as well as the total toxicity of applied chromium compound (Figs. 4 and 5).

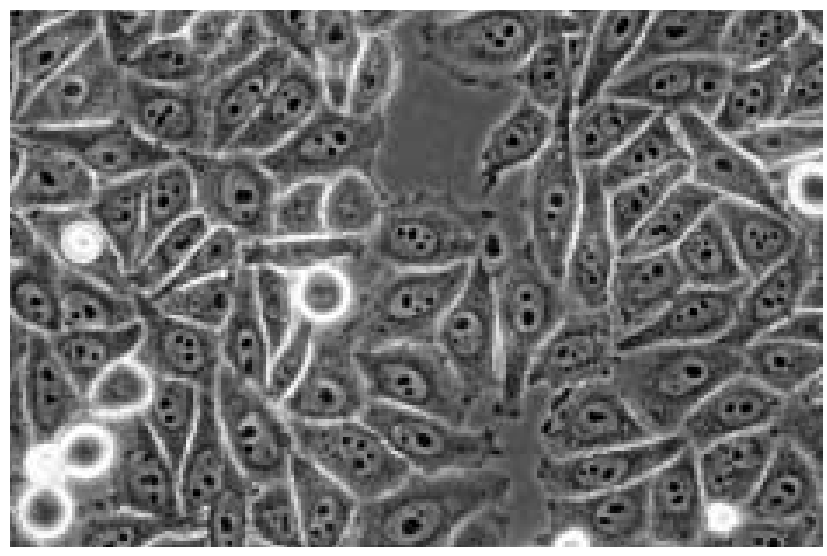

Fig. 2B: Morphology of human epitelioid laryngeal Hep-2 cells - control two weeks after the beginning of treatment. Phase contrast $400 \mathrm{x}$. 

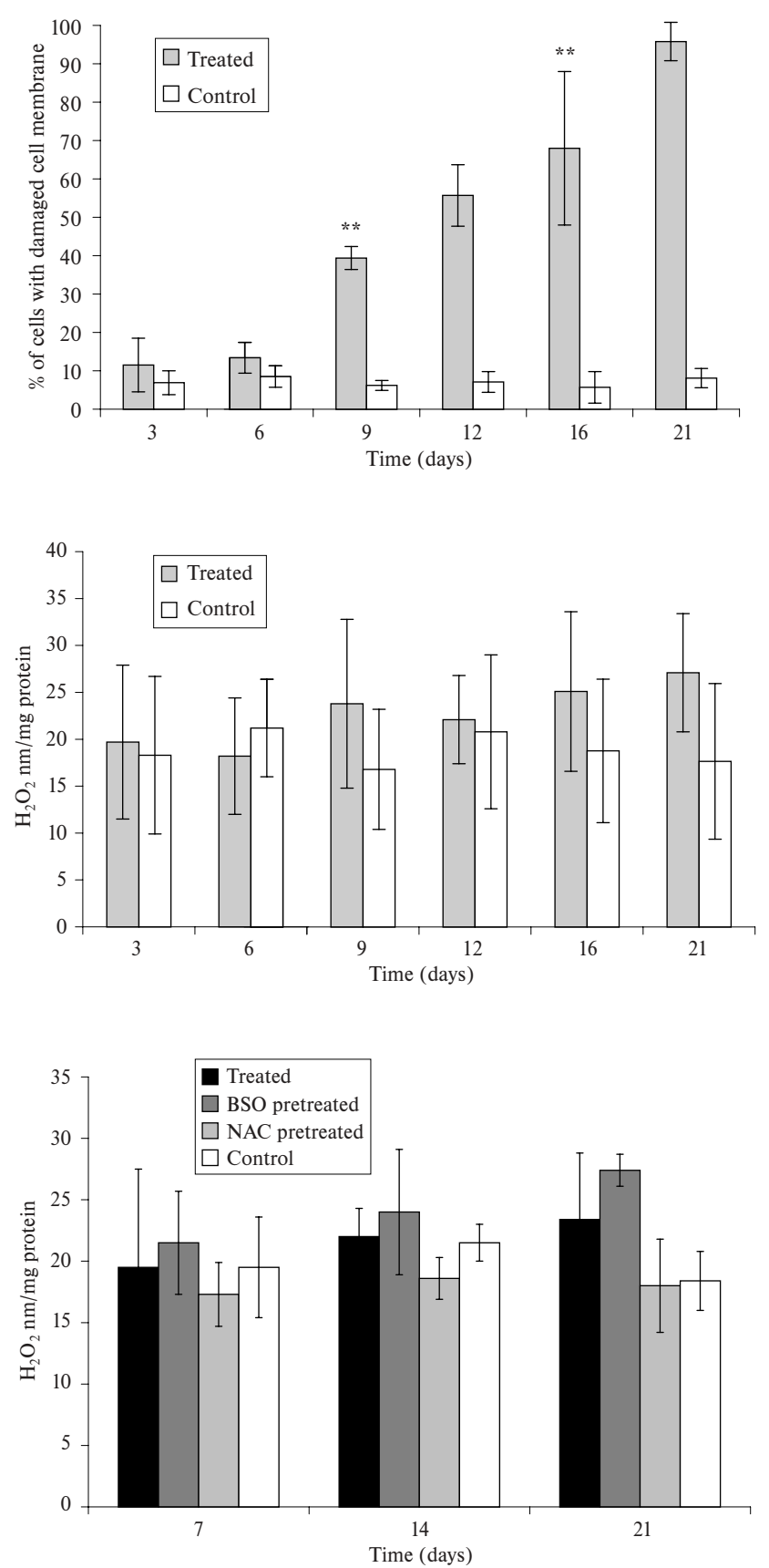

Induction of cell death by chromium acetate hydroxide. The first morphological features of severe cell injury and death became massively apparent in cells at the beginning of the third week of treatment with $1 \mathrm{mM}$ chromium acetate hydroxide. Rapid cell rounding with complete absence of any membrane figures or, conversely, with very specific cytoplasmic protrusions gradually affected all the exposed cells. Observed changes in F-actin cables as revealed by phalloidin staining were haphazard and dissimilar to any others described insofar for apoptosis (Fig. 6).
Fig. 3: The integrity of Hep-2 cells membrane after treatment with $1 \mathrm{mM}$ chromium acetate hydroxide during 3 weeks. The treated cells were detached from the cultivation flask, resuspended in fresh medium and stained with acridine orange/ethidium bromide solution for $5 \mathrm{~min}$. The suspension was transferred onto a slide and examined microscopically. For each experiment, at least 500 cells were scored. The proportion of cells with damaged cell membranes was expressed as \% of ethidium bromide-positive cells. Values represent the mean \pm SD of three different experiments. ${ }^{* *} \mathrm{P}<0.01$ with one way-Anova test and Dunnet's post test for multiple comparisons.

Fig. 4: The levels of hydrogen peroxide in human epitelioid laryngeal Hep-2 cells exposed to $1 \mathrm{mM}$ chromium acetate hydroxide during 3 weeks. The cells were grown in a 96multiwell plate and oxidative stress was measured spectrophotometrically at $620 \mathrm{~nm}$. Values represent the mean \pm SD of three different experiments. ${ }^{*} \mathrm{P}<0.01$ with one way-Anova test and Dunnet's post test for multiple comparisons.

Fig. 5: The effect of glutathione depletion and glutathione enhancement on $1 \mathrm{mM}$ chromium acetate hydroxide generated oxidative stress in human epitelioid laryngeal Hep-2 cells. The cells were grown in a 96-multiwell plate, pretreated with glutathione depleting buthionine sulfoximine (BSO) or glutathione enhancing $\mathrm{N}$-acetylcystein (NCA) and oxidative stress was measured spectrophotometrically at 620 $\mathrm{nm}$. Values represent the mean $\pm \mathrm{SD}$ of three different experiments. ${ }^{* *} \mathrm{P}<0.01$ with one way-Anova test and Dunnet's post test for multiple comparisons.

Specific immunofluorescent detection of caspase-3 in thus treated cells showed only weak response - $20 \%$ positivity (Fig. 7).

Changes in chromatin structure and general appearance of nuclei of treated versus control cells were monitored by DNA-specific dye DAPI which selectively binds to A-T rich regions. When exposed to $1 \mathrm{mM}$ chromium acetate hydroxide, nuclear chromatin shrank or became dispersed. In addition, only about $20 \%$ of cells were found with marginalized and/or fragmented chromatin, suggesting the prevalence of necrotic nuclei (Fig. 8). 


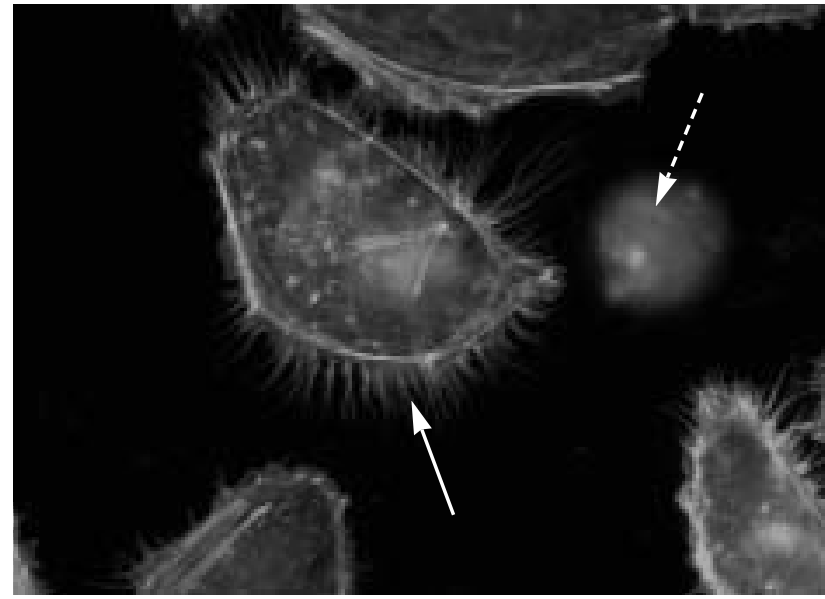

Fig. 6A: The architecture of F-actin cytoskeleton in human epitelioid laryngeal Hep-2 cells two weeks after the beginning of treatment with $1 \mathrm{mM}$ chromium acetate hydroxide. F-actin is reduced in the center of cell; the cell membrane produces spike-like protrusions (full arrow). Chromatin fragmentation is visible (dashed arrow). Immunofluorescence staining FITC-conjugated phalloidin. 600x.

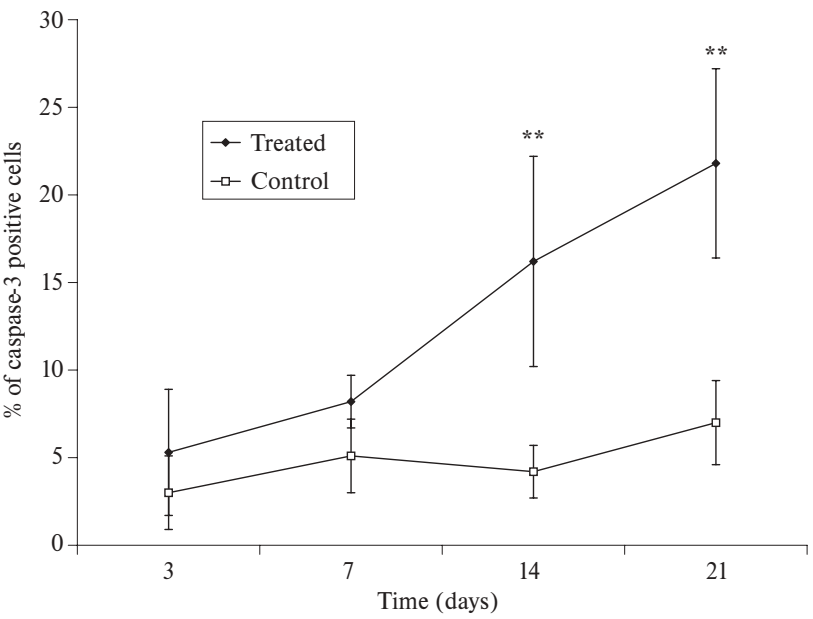

Fig. 7: The presence of the activated caspase-3 in human epitelioid laryngeal Hep- 2 cells exposed to $1 \mathrm{mM}$ chromium acetate hydroxide during 3 weeks. The chromium-treated cells were seeded into cytospin chambers and at given time intervals immunofluorescence detection of the activated caspase-3 was carried out with subsequent microscopic analysis. Values represent the mean \pm SD of three different experiments. ${ }^{*} \mathrm{P}<0.01$ with one way-Anova test and Dunnet's post test for multiple comparisons.

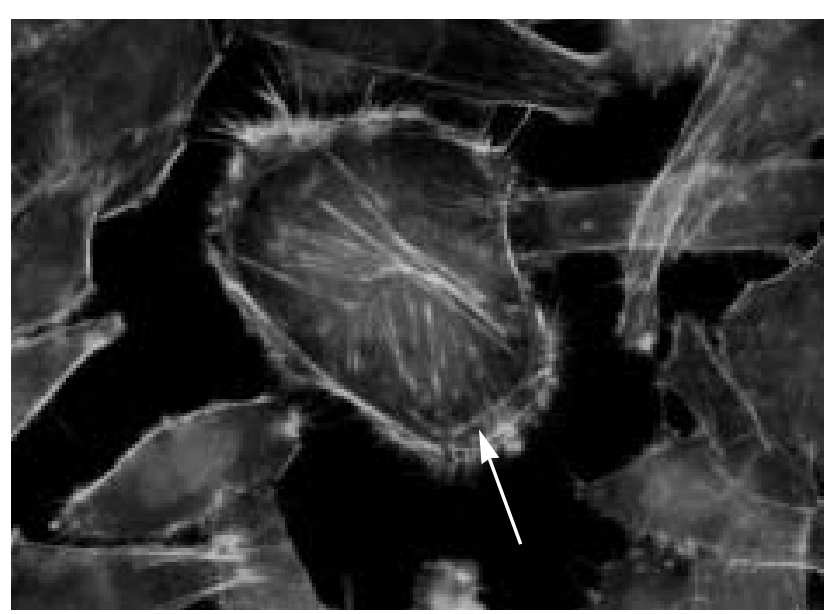

Fig. 6B: The architecture of F-actin cytoskeleton in human epitelioid laryngeal Hep-2 cells - control. The main area of F-actin localization is in the center and on the edges of the cell (arrow). Immunofluorescence staining FITC-conjugated phalloidin. 600x.

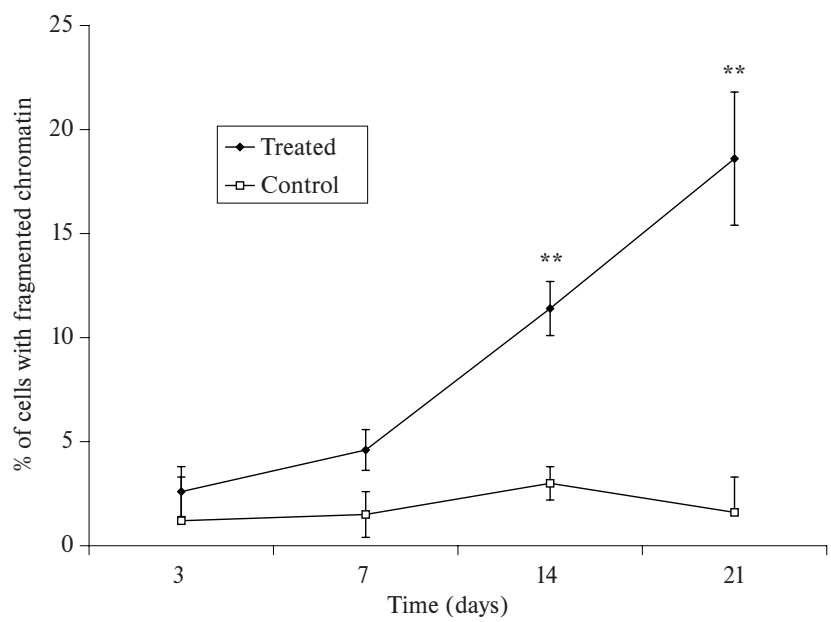

Fig. 8: Chromatin fragmentation in $1 \mathrm{mM}$ chromium acetate hydroxide treated human epitelioid laryngeal Hep-2 cells during 3 weeks. The treated cells were detached from the cultivation flask, resuspended in fresh medium and stained with DAPI solution for 5 min. The suspension was transferred onto a slide and examined microscopically. For each experiment, at least 500 cells were scored. Values represent the mean $\pm \mathrm{SD}$ of three different experiments. ${ }^{* *} \mathrm{P}<0.01$ with one way-Anova test and Dunnet's post test for multiple comparisons. 


\section{Discussion}

In the cell, chromium may exist in different valence states whose life span, reactivity and toxicity vary. $\mathrm{Cr}$ (III) represents the ultimate valence state of this element arising from enzymatically catalyzed reduction of $\mathrm{Cr}(\mathrm{VI})$ by various cellular systems. Cr (III) is capable of interacting with DNA molecules as well as with other intracellular targets, thus producing pathological changes which are responsible for the documented cytotoxicity and genotoxicity of this element $(6,20,21,27,31)$. While Cr (III) induced DNA alterations have been thoroughly documented in vitro, its cytotoxic and genotoxic potentials have been found almost negligible in different model systems comprising both cell cultures and animals $(6,23)$. This dichotomy is nowadays explained by inability of $\mathrm{Cr}$ (III) ions to penetrate inside the cell due to the absence of any specific transport means as with $\mathrm{Cr}$ (VI).

The purpose of this work was to verify a hypothesis whether longer exposures to subtoxic chromium acetate hydroxide change the structure of human laryngeal Hep-2 cell membranes, thereby allowing better $\mathrm{Cr}$ (III) permeability. Furthermore, the types and mechanisms of chromium acetate hydroxide induced intracellular changes along with the final cellular fate were focused too.

In our previous work we showed that chromium acetate hydroxide at common concentration range found in industrially generated wastes is capable of inducing cell death in Hep-2 cells (18). The speed and nature of this process depend on the employed concentration as higher doses induced quick changes resulting in fixation while lower doses produced slower death bearing the features of necrosis; i.e. cell swelling, random chromatin degradation and so forth. The limiting concentration of chromium acetate hydroxide causing no traceable changes in our model has been established to $1 \mathrm{mM}$. Still, when compared to other studies carried out with the same compound but on different models it becomes obvious that there may exist varying sensitivity to $\mathrm{Cr}$ (III) in different cell types, with for example lymphocytes or hepatocytes being several fold more sensitive than Hep-2 cells (5).

Some recently published reports show that another limiting factor of $\mathrm{Cr}$ (III)-dependent toxicity derives from its chemical ligand, which may modify both positively or negatively the transport of $\mathrm{Cr}$ (III) ions across the plasma membrane $(1,2)$. This former type of interaction in particular is nowadays seriously investigated due to the expected longer term use of some $\mathrm{Cr}$ (III) preparations as a dietary supplement. One of them is chromium picolinate which is routinely recommended to enhance insulin activity by facilitating glucose entry into the cell $(9,12)$. Until recently, this preparation was considered absolutely safe and no experimental as well as clinical evidence of its toxicity was known. Nevertheless, picolinic acid in combination with $\mathrm{Cr}$ (III) most probably holds controversial potential which may be responsible for the observed mitochondrial damage and apoptosis in Chinese hamster ovary cells. Chromium picolinate and its long-term effects are therefore under intensive investigation as it is not yet known whether its proapoptotic activity is due to the activity of picolinic acid only or combination of both $(1,12,21,22)$.

Chromium acetate hydroxide at employed concentration of $1 \mathrm{mM}$ produced during the first weak of treatment no observable changes, suggesting a very limited entry of $\mathrm{Cr}$ (III) ions to the cells. The plasma membrane remained intact and cells normally proliferated although this proliferation has been slowed when compared to control cultures. A question might therefore be raised whether $\mathrm{Cr}$ (III) ions alone or in combination with acetate hydroxide ligand do not interfere with extracellular signals regulating mitosis or, alternatively, they do not cause discrete changes in the structure of the plasma membrane, thus allowing similar interference intracellularly. In our opinion, permanent presence of chromium acetate hydroxide more likely interferes with the normal functioning of the cell membrane which becomes more affected with advancing time of treatment. This hypothesis is supported by our finding of changed behavior of Hep-2 cells during the second and third weeks of treatment with chromium acetate hydroxide. The increased permeability and altered morphological appearance of the cell membrane (Figs. 1 and 2) clearly point at this structure as being the main initial target of chromium acetate hydroxide toxicity.

Several Cr (III) compounds have been evidenced as apoptosis inducers. The activation of apoptosis in the presence of $\mathrm{Cr}$ (III) complexes containing aromatic amine and Schiff base ligands has been associated with oxidative stress mediating activation of Src-family tyrosine kinases and subsequent transduction of other proapoptotic signals $(2,17)$. It seems that various $\mathrm{Cr}$ (III) compounds may initiate the production of free oxygen radicals via the Fenton chemistry, thereby triggering the cell degradation cascade $(24,26)$. We have measured the production of hydrogen peroxide - an important indicator of oxidative stress in Hep-2 treated cells as shown in Fig 4. Hydrogen peroxide levels were found to be slightly elevated in chromium acetate hydroxide treated cells, in particular during the second and the third weeks of the treatment, but this increase was not statistically significant in comparison with control cells. Intracellular reduced glutathione is an important quencher of free radicals and its depletion has been observed upon induced oxidative stress during apoptosis or other pathological processes $(10,30)$. On the other hand, higher content of glutathione has been shown to protect cells against oxidative stress and apoptosis $(10,16,25)$. In our experimental model, pretreatment of Hep-2 cells with BSO - glutathione depleting and NAC-glutahione enhancing chemicals had no measurable effect on morphology and survival of treated cells. Taken together, these results indicate that oxidative stress most possibly plays a minor role during chromium acetate hydroxide induced cell death. 
The morphological appearance of the dying cells, which have became more frequently seen from the second week of treatment, testified to a high degree of individual variability. On one hand, there were very few findings of classical apoptotic cells with typical membrane blebs; on the other hand, many cells expressed rather specific membrane degradation and shrinkage or a combination of both. Also, this degradation clearly involved F-actin fibers and seems to refer to actin cytoskeleton as other important target of chromium acetate hydroxide toxicity (Fig. 6). Assessment of mitochondrial and lysosomal activity indicated their altered function (unpublished observations) which agrees with other published papers $(8,9,14)$. Analyses of chromatin structure revealed that the typical apoptotic chromatin fragmentation occurred in only about $20 \%$ of cells, with the remaining population showing necrosis-like chromatin degradation. Furthermore, the activation of caspase-3, an execution apoptosis enzyme, was also present in approximately $20 \%$ of treated cells.

These findings may somewhat differ from other papers dealing with toxicity of chromium compounds in several ways. Firstly, we show that chromium acetate hydroxide at moderate dose of $1 \mathrm{mM}$ has membrane-injuring effect combined possible with F-actin degradation which translates into later cell degradation and death.

Secondly, this membrane and F-actin injuring effect as well as other observed pathological changes develop slowly and do not prevent (at least initially) cell division. According to our observations, Hep-2 cells require approximately four rounds of cell division in the presence of tested compound before they begin to deteriorate. Overall, this points at possible cumulative effect of $\mathrm{Cr}$ (III) ions as it has been observed previously $(4,13)$ but further in this case with unclear participation of acetate hydroxide ligand.

Thirdly, such chronic exposure produces cell death bearing features of apoptosis and necrosis in different cells of the same treated population. This phenomenon is no longer new as there are reports showing that cell death may take different forms upon specific conditions (7), in particular with respect to varying involvement of lysosomes or mitochondria. In addition, chromium acetate hydroxide stimulated cell death does not seem to be activated exclusively through oxidative stress and this might explain low apoptotic positivity in treated cells.

\section{Conclusion}

In summary, chronic exposure to chromium acetate hydroxide produces degenerative changes in Hep- 2 cells, mainly via damaged cell membranes. The nature and appearance of damaged and dying cells indicate a distinct type of cell death bearing the features of apoptosis and necrosis or both. Besides cell membranes, chromium acetate hydroxide interferes with several intracellular targets but its ability to generate oxidative stress seems to be limited.

\section{Acknowledgement}

This work was supported by Ministry of Education Czech Republic Research Project MSM 111500001 Serious organ failure, experimental and clinical aspects, possibilities for prevention and therapeutic management.

\section{References}

1. Bagchi D, Bagchi M, Balmoori J, Ye X, Stohs SJ. Comparative induction of oxidative stress in cultured J774A.1 macrophage cells by chromium picolinate and chromium nicotinate. Res Commun Mol Pathol Pharmacol 1997;97:335-46.

2. Balamurugan K, Rajaram R, Ramasami T, Narayanan S. Chromium (III)-induced apoptosis of lymphocytes: death decision by ROS and Src-family tyrosine kinases. Free Radic Biol Med 2002;33:1622-40.

3. Barnhart J. Occurrences, uses, and properties of chromium. Regul Toxicol Pharmacol 1997;26:3-7.

4. Biedermann KA, Landolph JR. Role of valence state and solubility of chromium compounds on induction of cytotoxicity, mutagenesis, and anchorage independence in diploid human fibroblasts. Cancer Res 1990;50:7835-42.

5. Dartsch PC, Hildenbrand S, Kimmel R, Schmahl FW. Investigations on the nephrotoxicity and hepatotoxicity of trivalent and hexavalent chromium compounds. Int Arch Occup Environ Health 1998;71(Suppl):40-5.

6. Dillon CT, Lay PA, Bonin AM, Dixon NE, Sulfab Y. DNA interactions and bacterial mutagenicity of some $\mathrm{Cr}$ (III) complexes and their $\mathrm{Cr}(\mathrm{V})$ analogues: evidence for $\mathrm{Cr}(\mathrm{V})$ intermediates in the genotoxicity of $\mathrm{Cr}$ (III). Aust J Chem 2000; 53:411-24

7. Formigli L, Papucci L, Tani A et al. Aponecrosis: morphological and biochemical exploration of a syncretic process of cell death sharing apoptosis and necrosis. J Cell Phys 2000;182:41-9.

8. Gunaratnam M, Grant MH. Chromium (VI)-induced damage to the cytoskeleton and cell death in isolated hepatocytes. Biochem Soc Trans 2002;30:748-50.

9. Hepburn DD, Vincent JB. Tissue and subcellular distribution of chromium picolinate with time after entering the bloodstream. J Inorg Biochem 2003:94:86-93.

10. Chen Q, Chai YC, Mazumder S et al. The late increase in intracellular free radical oxygen species during apoptosis is associated with cytochrome c release, caspase activation, and mitochondrial dysfunction. Cell Death Differ 2003; $10: 323-34$

11. Kortenkamp A, Beyersman D, O(Brien P. Uptake of chromium (III) complexes by erythrocytes. Toxicol Environ Chem 1983;14:23.

12. Manygoats KR, Yazzie M, Stearns DM. Ultrastructural damage in chromium picolinate-treated cells: a TEM study. J Biol Inorg Chem 2002;7:791-8

13. Medeiros MG, Rodrigues AS, Batoreu MC, Laires A, Rueff J, Zhitkovich A Elevated levels of DNA-protein crosslinks and micronuclei in peripheral lymphocytes of tannery workers exposed to trivalent chromium. Mutagenesis 2003; 18:19-24.

14. Messer RL, Lucas LC. Evaluations of metabolic activities as biocompatibility tools: a study of individual ions' effects on fibroblasts. Dent Mater 1999;15:1-6.

15. Newbold RF, Amos J, Connell JR. The cytotoxic, mutagenic, and clastogenic effects of chromium containing compounds on mammalian cells in culture. Mutat Res 1979;67:55-63.

16. Pourahmad J, O'Brien PJ. Biological reactive intermediates that mediate chromium (VI) toxicity. Adv Exp Med Biol 2001;500:203-7.

17. Rajaram R, Nair BU, Ramasami T. Chromium (III)-induced abnormalities in human lymphocyte cell proliferation: evidence for apoptosis. Biochem Biophys Res Commun 1995;210:434-40.

18. Rudolf E, Peychl J, Červinka M. Toxic effects of chromium acetate hydroxide on cells cultivated in vitro. Altern Lab Anim 2001;29:163-77.

19. Rudolf, E, Červinka, M. Time dependent appearance of selected apoptotic markers and usefulness of their detection in vitro. Acta Medica (Hradec Králové) 2002;45:135-44.

20. Snow ET. Effects of chromium on DNA replication in vitro. Environ Health Perspect 1994;102(Suppl 3):41-4

21. Stearns DM, Silveira SM, Wolf KK, Luke AM. Chromium (III) tris(picolinate) is mutagenic at the hypoxanthine (guanine) phosphoribosyltransferase locus in Chinese hamster ovary cells. Mutat Res 2002;513:135-42.

22. Stearns DM, Wise JP Sr, Patierno SR, Wetterhahn KE. Chromium (III) picolinate produces chromosome damage in Chinese hamster ovary cells. FASEB J 1995;9:1643-8

23. Stohs SJ, Bagchi D, Hassoun E, Bagchi M. Oxidative mechanisms in the toxicity of chromium and cadmium ions. J Environ Pathol Toxicol Oncol 2000;19: 201-13

24. Sugden KD, Geer RD, Rogers SJ. Oxygen radical-mediated DNA damage by redox-active Cr (III) complexes. Biochemistry 1992;31:11626-31.

25. Swamy SM, Huat BT. Intracellular glutathione depletion and reactive oxygen species generation are important in alpha-hederin-induced apoptosis of P388 cells. Mol Cell Biochem 2003;245:127-39. 
26. Tsou TC, Yang JL. Formation of reactive oxygen species and DNA strand breakage during interaction of chromium (III) and hydrogen peroxide in vitro: evidence for a chromium (III)-mediated Fenton-like reaction. Chem Biol Interact 1996; 102:133-53

27. Warren G, Schultz P, Banckroft D, Bennet K, Abbot EH, Rogers S. Mutagenicity of a series of hexacoordinate chromium (III) compounds. Mutat Res 1981; 90:111-22.

28. Wise JP Sr, Wise SS, Little JE. The cytotoxicity and genotoxicity of particulate and soluble hexavalent chromium in human lung cells. Mutat Res 2002;517: $221-9$.

29. Xie Y, Zhuang ZX. Chromium (VI)-induced production of reactive oxygen species, change of plasma membrane potential and dissipation of mitochondria membrane potential in Chinese hamster lung cell cultures. Biomed Environ Sci 2001;14:199-206.

30. Ye J, Wang S, Leonard SS, Sun Y et al. Role of reactive oxygen species and p53 in chromium (VI)-induced apoptosis. J Biol Chem 1999;274:34974-80.

31. Zhitkovich A, Quievryn G, Messer J, Motylevich Z. Reductive activation with cysteine represents a chromium (III)-dependent pathway in the induction of ge- notoxicity by carcinogenic chromium (VI). Environ Health Perspect 2002; 110(Suppl 5):729-31.

Submitted June 2003.

Accepted August 2003.

PharmDr. Emil Rudolf, Ph.D.

Charles University in Prague, Faculty of Medicine in Hradec Králové, Department of Medical Biology and Genetics, Šimkova 870, 50038 Hradec Králové, Czech Republic. e-mail: rudolf@lfhk.cuni.cz 